\title{
Pengaruh Sifat Materialisme terhadap Perilaku Impulsive Buying dan Kecenderungan Compulsive Buying Pada Remaja di Kota Mataram
}

\author{
Rini Anggriani \\ rinianggriani@universitabumigora.ac.id \\ Universitas Bumigora \\ Abdurrahman \\ abdurrahman@universitasbumigora.ac.id \\ Universitas Bumigora \\ Isra Dewi Kuntary Ibrahim \\ israibrahim@universitasbumigora.ac.id \\ Universitas Bumigora \\ Raden Bagus Faizal Irany Sidharta \\ raden.sidharta@universitasbumigora.ac.id \\ Universitas Bumigora
}

\begin{abstract}
Abstrak
The phenomenon of consumers' behavior in shopping as the effect of the Covid-19 pandemic from offline to online indirectly has an impact on the prevalence of the increasing number of internet users in Indonesia. This study aims to identify whether there is a psychological influence of consumers such as the nature of materialism on impulsive buying and compulsive buying tendencies among adolescents in Mataram City. The sampling technique used was the purposive sampling method with a sample of 110. Data analysis used Structural Equation Modeling (SEM). The results showed that there was a positive and significant influence and relationship between the nature of materialism and impulsive buying. There is a positive and significant effect of materialism on compulsive buying tendencies. There is a positive and significant influence of impulsive buying on the tendency of compulsive buying in local teenagers in Mataram City.
\end{abstract}

Keywords: compulsive buying, impulsive buying, materialism

\section{Pendahuluan}

Data BPS yang dimuat dalam Asosiasi Penyelegara Jasa Internet Indonesia (APJII) 20192020 (Q2) menujukan bahwa penetrasi penggunaan internet terus meningkat yakni sebesar 196,71 juta jiwa dari total 266,91 juta jiwa penduduk indonesia atau sekitar $73,7 \%$ dengan sebaran jenis kelamin perempuan 50,2\%, laki-laki 49,8\% yang aktif mengunakan internet. Data ini mengalami kenaikan sebesar 8,9\% dari tahun sebelumnya pada tahun 2018 meningkat hanya sebesar 1,03\%. Peningkatan ini berdampak juga di NTB yakni $68.5 \%$ pada tahun 2018 meningkat menjadi $73,1 \%$ pada tahun $2019-2020$. Peningkatan jumlah penguna ini dibarengi pula dengan boomingnya toko belanja online diseluruh Indonesia termasuk Kota Mataram.

Fenomena tersebut, secara tidak langsung membawa trend gaya hidup serta pola kebiasaan baru masyarakat modern, termasuk kalangan remaja. Aktivitas belanja masyarakatpun mengalami pergeseran demikian cepat dari offline kini sudah banyak beralih ke belanja secara online. Disaat yang sama pemasaran online memanfaatkan peluang tersebut dengan menawarkan berbagai kemudahan pemesanan, variasi produk yang beragam, diskon serta desain situs web yang menarik sehingga cenderung membuat siapa saja rentan dan cepat tergoda untuk melakukan pembelian, baik yang terencana maupun tidak terencana atau pembelian dengan spontan (implusif buying). Dalam penelitian Anggriani (2017), impulsive buying apabila dilakukkan dalam jangka waktu yang panjang akan menjadikannya sebagai 
perilaku pembeli yang berlebihan dan secara terus menerus dalam frekuensi yang tinggi dapat mengarah pada kecenderungan compulsive buying.

Penelitian empiris yang dilakukan Adamczyk, dkk (2020) dengan sampel penelitian pada remaja Polandia menunjukkan bahwa anak muda atau remaja millenial rentan melakukan compulsive buying dibandingkan orang dewasa dan orang tua. Ini berarti compulsive buying sering kali menjadi respon remaja atas perkembangan yang ada sebagai bentuk peningkatan harga diri dan mendapatkan pengakuan sebagai penciri dari orientasi materialisme yang jika sering dilakukan berpontensi memicu terjadinya compulsive buying dikalangan remaja. Berdasarkan kajian empiris yang dilakukan oleh Eren, dkk (2012), Alqurianisha, dkk (2020), Shahid, dkk (2012), Prawira dkk (2015), menyatakan bahwa sifat materialisme berpengaruh positif dan signifikan terhadap impusive buying. Hasil temuan Ahn \& Kwon (2020), teori sifat, emosi/perasaan memiliki dampak pada pengaruh positif dan negatif terhadap perilaku impulsive buying. Turkyilmaz, dkk (2015) melakukan penelitian dengan sampel responden di negara Turki mengatakan faktor psikologis konsumen seperti sifat materialisme dapat memicu seseorang melakukkan impulsive buying. Penelitian Anggriani (2017) mengungkap psikologis konsumen seperti sifat materialisme memiliki pengaruh yang positif signifikan terhadap impulsive buying dan kecenderungan compulsive buying.

Perilaku impulsive dan compulsive, meski serupa namun bukanlah masalah yang sama. Impulsive buying adalah pembelian yang ditentukan oleh rangsangan luar sedangkan dalam kasus compulsive buying, keinginan untuk membeli berasal dari dalam, mungkin perasaan cemas dan individu tersebut ingin merasa tenang, atau mungkin membeli untuk membuat diri merasa lebih bahagia, lebih baik, dan sebagainya. Di sisi lain, menurut Balik, dkk (2020), compulsive buying cenderung tidak menolak untuk impulsive yang terkait dengan perasaan positif, seperti kenikmatan, kepuasan dan kelegaan.

Terlepas dari prevalensi internet dalam kehidupan kita sehari-hari, serta adanya perubahan perilaku belanja konsumen yang biasanya offline kini beralih ke online sebagai dampak dari adanya Covid-19 masih sangat sedikit yang diketahui tentang perilaku pembelian konsumen dalam pembelian online. Selain itu, menurut penelitian yang dilakukan Bighiu, dkk (2015) dengan sampel responden di Rumania, gangguan pembelian konsumen merupakan salah satu kecanduan baru, namun masih kurang diteliti. Floh \& Madlberger (2013) melakukan penelitian terkait impulsive buying secara online yang masih sangat jarang diteliti. Jefrey dan Hodge (2007) dalam Anggriani (2017) menyatakan bahwa sebagian besar penelitian yang telah ada terkait impulsive buying selama ini hanya difokuskan pada belanja offline. Bagaimana dengan psikologi perilaku impulsive buying dan compulsive buying remaja lokal di Kota Mataram? Penelitian ini hadir untuk menjawab gap tersebut. Penelitian ini bertujuan untuk mengidentifikasi apakah terdapat pengaruh psikologis konsumen seperti sifat materialisme terhadap impulsive buying dan kecenderungan compulsive buying secara online pada remaja di Kota Mataram.

\section{Tinjauan Pustaka}

\subsection{Sifat Materialisme}

Konsumen dengan nilai materialisme yang tinggi meyakini bahwa benda material merupakan hal yang sangat penting bagi hidup mereka. Dalam penelitian Anggriani (2017) menyatakan bahwa sifat materialisme yang ada dalam diri konsumen, menjadi salah satu faktor yang menyebabkan timbulnya impulsive buying. Konsumen yang materialistik juga akan cenderung berbelanja untuk membeli barang yang dirasa akan meningkatkan derajatnya tanpa berpikir panjang dan tanpa rencana sebelumnya. Semakin tinggi sifat materialisme yang dimiliki, maka semakin kuat pula kecenderungan untuk tidak dapat menunda suatu pembelian yang mengarah pada compulsive buying (Anggriani, 2017). Ini dikarenakan kepemilikan terhadap suatu benda menjadi sesuatu kebanggaan tersendiri. Materialisme yang merupakan salah satu ciri-ciri yang paling penting telah menjadi subyek dari banyak penelitian yang berdampak pada impulsive buying (Richins \& Dawson, 1992). 


\subsection{Impulsive Buying}

Perilaku impulsive buying adalah perilaku yang membeli barang/jasa secara spontan atau tidak direncanakan sebelumnya (Made \& Purnama, 2019). Dalam penelitian yang sama mengungkapkan bahwa berbelanja dapat mengubah mood seseorang, menghilangkan stres atau menghilangkan rasa bosan. Kebanyakan berbelanja menciptakan perilaku pembelian yang tidak direncanakan atau perilaku impulsive buying. Menurut Minor \& Minor (2012), impulsive buying adalah tindakan membeli yang sebelumnya tidak diakui secara sadar sebagai hasil suatu pertimbangan atau niat membeli yang terbentuk sebelum memasuki toko.

\subsection{Compulsive Buying}

Minor (2012) menyatakan bahwa compulsive buying dapat didefinisikan sebagai "respon terhadap dorongan yang tidak terkendali atau keinginan untuk memperoleh, menggunakan, atau mengalami suatu perasaan, substansi atau kegiatan yang menuntun individu untuk secara berulang kali terlibat dalam perilaku yang akhirnya merugikan individu atau individu yang lain". Compulsive buying dapat mempengaruhi psikologis individu misalnya seperti munculnya rasa gelisah, depresi, frustasi dan konflik interpersonal dan lain sebagainya (Anggriani, 2017). Jadi, dapat disimpulkan bahwa compulsive buying merupakan suatu pembelian berulang dan berlebihan serta cenderung pada pemborosan, di mana pembelian dilakukan tidak hanya semata-mata untuk mendapatkan barang atau produk melainkan lebih kepada kepuasan untuk menghilangkan perasaan atau suasana hati yang tidak menyenangkan

\subsection{Hubungan Antar Variabel}

Kajian empiris dilakukan oleh Eren, et al. (2012), Alqurianisha, et al. (2020), Shahid, et al. (2012), Prawira, et al. (2015), di mana penelitian tersebut menunjukkan sifat materialisme berpengaruh positif dan signifikan terhadap impusive buying. Hasil temuan Ahn \& Kwon (2020), menunjukkan teori sifat, emosi/perasaan memiliki dampak pada pengaruh positif dan negatif terhadap perilaku impulsive buying. Turkyilmaz, et al. (2015) menyatakan bahwa faktor psikologis konsumen seperti sifat materialisme dapat memicu seseorang melakukkan impulsive buying. Penelitian Anggriani (2017) mengungkap psikologis konsumen seperti sifat materialisme memiliki pengaruh yang positif signifikan terhadap impulsive buying dan kecenderungan compulsive buying. Kajian Turkyilmaz, et al. (2015) dalam Anggriani, dkk (2020) menemukan bahwa suasana kepribadian seseorang dapat memicu terjadinya impulsive buying. Sehingga diajukan hipotesis penelitian sebagai berikut :

$\mathrm{H} 1 \rightarrow$ Terdapat pengaruh sifat materialisme terhadap impulsive buying remaja yang berbelanja online.

$\mathrm{H} 2 \rightarrow$ Terdapat pengaruh sifat materialisme terhadap compulsive buying remaja yang berbelanja online.

$\mathrm{H} 3 \rightarrow$ Terdapat pengaruh impulsive buying terhadap compulsive buying remaja yang berbelanja online.

\subsection{Kerangka Konseptual}

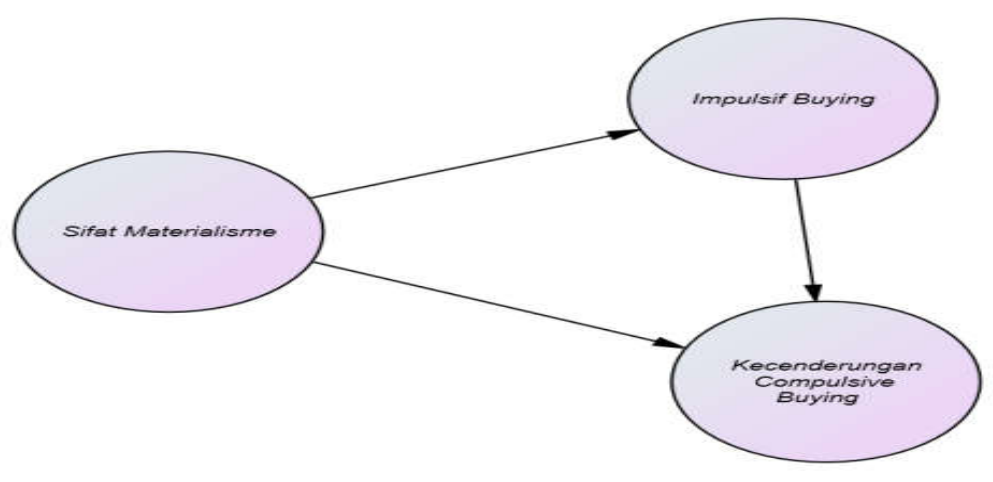

Gambar 1. Kerangka Konseptual 


\section{Metode Penelitian}

Penelitian ini merupakan penelitian kausalitas. Populasi pada penelitian ini adalah remaja yang pernah melakukan belanja secara online dengan sampel responden sebanyak 110 responden. Teknik pengambilan sampel menggunakan metode purposive sampling. Dengan kriteria merupakan remaja berusia 15-25 tahun, sudah pernah melakukan belanja secara online khususnya pembelian produk yang sama dengan intensitas minimal 4 kali dalam 1 bulan terakhir. Alat pengumpulan data mengunakan kuesioner skala likert point 1-5 (Sangat Tidak Setuju sampai dengan Sangat Setuju). Pada penelitian ini dilakukan uji validitas dan reliabilitas. Dalam penelitian ini dilakukan juga Uji Kaiser Meyer Olkin (KMO) and Bartlett's Test. Uji ini dilakukan untuk mengetahui seberapa layak data yang dimiliki untuk dianalisis lebih lanjut.

Adapun teknik analisis data menggunakan Structural Equation Modeling (SEM) dengan software AMOS Versi 21. Hasil uji full model SEM dengan menggunakan goodness of fit dengan kriteria cut off value yang dilihat dari nilai Chi-square yang semakin kecil semakin baik. RMSEA (Root Mean Square Error Of Aproximation) <0,08, GFI (goodness of fit index) nilai GFI $\geq 0,9$ merupakan good fit, sedangkan 0,8 $\leq$ GFI $\geq 0,9$ disebut sebagai marginal fit atau model dapat diterima, AGFI (Adjusted Goodness Of Fit Index) dengan nilai 0,9 (AGFI $\geq 0,9$ ) dikatakan fit, marginal apabila memiliki AGFI, $0,8 \leq$ AGFI $\leq 0,9)$, CMIN/DF yang diharapkan adalah kurang dari atau sama dengan 2.00, TLI (Tucker Lewis Index) Nilai TLI berkisar antara 0 sampai 1 . Nilai TLI $\geq 0,9$ merupakan good fit sedangkan nilai TLI, $0,8 \leq$ TLI $\leq 0,9$ dikatakan marginal fit dan CFI (Comparative Fit Index) model dikatakan good fit apabila nilai CFI lebih besar atau sama dengan 0,9 (CFI $\geq 0,9$ ) dan dikatakan marginal fit apabila nilai CFI, 0,8 $\leq$ CFI $\leq 0,9$, IFI (Incremental Fit Index) $\geq 0,90$, NFI (Normed Fit Index) $\geq 0,90$ (Ferdinand, 2014).

\section{Analisis dan Pembahasan}

\subsection{Analisis Data}

\subsubsection{Hasil Uji Validitas}

Pengujian validitas bertujuan untuk mengetahui apakah semua pernyataan dalam instrumen penelitian yang diajukan untuk mengukur variabel penelitian merupakan pertanyaan atau pernyataan yang seharusnya diajukan. Uji validitas berkaitan dengan akurasi atau ketepatan alat ukur penelitian. Pengujian validitas instrumen dilakukan menggunakan koefisien korelasi pearson dengan SPPS dan Pengujian yang dilakukan menghasilkan koefisien korelasi yang signifikan dengan tingkat sig diatas 5\%, sehingga dapat disimpulkan bahwa butir-butir instrumen penelitian valid.

Uji validitas kedua dalam penelitian ini mengunakan uji validitas konvergen dengan menggunakan Confirmatory Faktor Analysis (CFA). CFA meliputi model pengukuran yang mengambarkan hubungan antara variabel yang diteliti dan konsep atau variabel laten. Nilai validitas Konvergen dapat dilihat dari Faktor Loading setiap variabel yang diteliti. Nilai lamda $(\lambda)$ atau faktor loading lebih besar dari 0,40, apabila kurang dari 0,40 maka model perlu direvisi dengan mengeluarkan indikator variabel yang tidak memenuhi syarat (Ferdinand, 2014). Selanjutnya uji reliabiltas instrumen menggunakan koefisien Cronbach Alpha, dengan koefisien konsistensi internal minimum 0,60 (Taherdoost, 2016). 


\begin{tabular}{|c|c|c|c|c|c|}
\hline \multicolumn{6}{|c|}{ Tabel 1. Hasil Uji Korelasi Person dan Factor Loading dengan CFA } \\
\hline Variabel & Indicator & $\begin{array}{c}\text { Korelasi } \\
\text { Pearson } \\
\text { (SPSS) }\end{array}$ & $\begin{array}{c}\text { Faktor } \\
\text { Loding }(\lambda) \\
\text { (CFA-SEM) }\end{array}$ & $\begin{array}{c}\text { No } \\
\text { Item }\end{array}$ & Ket \\
\hline \multirow{5}{*}{$\begin{array}{c}\text { Sifat } \\
\text { Materialisme } \\
\text { (X) }\end{array}$} & $\begin{array}{l}\text { Kepemilikan barang penting dalam } \\
\text { hidup (x1) }\end{array}$ & 0,67 & 0,99 & 1 & Valid \\
\hline & $\begin{array}{l}\text { Membeli banyak barang membuat } \\
\text { bahagia (x2) }\end{array}$ & 0,68 & 0,99 & 2 & Valid \\
\hline & $\begin{array}{l}\text { Kepemilikan barang menunjukkan } \\
\text { status (x3) }\end{array}$ & 0,71 & 0,92 & 3 & Valid \\
\hline & $\begin{array}{l}\text { Merasa resah saat tidak sanggup } \\
\text { membeli barang yang disukai (x5) }\end{array}$ & 0,70 & 0,88 & 4 & Valid \\
\hline & $\begin{array}{l}\text { Membeli untuk menyenangkan diri } \\
\text { sendiri (x5) }\end{array}$ & 0,77 & 0,85 & 5 & Valid \\
\hline \multirow{4}{*}{$\begin{array}{c}\text { Impulsive } \\
\text { Buying (Y1) }\end{array}$} & Pembelian dengan spontan (y1.1) & 0,74 & 1,00 & 6 & Valid \\
\hline & $\begin{array}{l}\text { Pembelian tanpa berpikir akibat } \\
\text { (y1.2) }\end{array}$ & 0,78 & 1,02 & 7 & Valid \\
\hline & Pembelian terburu-buru (y1.3) & 0,68 & 0,98 & 8 & Valid \\
\hline & Pembelian dipengaruhi emosi (y1..4) & 0,76 & 0,94 & 9 & Valid \\
\hline \multirow{4}{*}{$\begin{array}{c}\text { Compulsive } \\
\text { Buying } \\
\text { (Y2) }\end{array}$} & Belanja untuk merasa lebih baik (y2.1) & 0,92 & 1,00 & 10 & Valid \\
\hline & Ingin menghabiskan uang (y2.2) & 0,89 & 0,97 & 11 & Valid \\
\hline & $\begin{array}{l}\text { Belanja tetapi tidak perduli apa yang } \\
\text { dibeli (y2.3) }\end{array}$ & 0,86 & 0,94 & 12 & Valid \\
\hline & Gelisah jika tidak belanja (y2.4) & 0,81 & 0,92 & 13 & Valid \\
\hline
\end{tabular}

\section{Sumber : Data primer diolah}

Hasil uji validitas korelasi person dan CFA menunjukkan semua item instrument penelitian untuk seluruh item-item pertanyaan dalam variabel merupakan item yang valid karena memiliki nilai korelasi dengan tingkat sig $\geq 0,50$ atau diatas $5 \%$.

\subsubsection{Hasil Uji Reliabilitas}

Uji reliabilitas berkaitan dengan pengukuran yang dibuktikan dengan menguji konsistensi dan stabilitas. Uji reliabilitas diartikan sebagai tingkatan dimana pengukuran yang digunakan bebas dari random error dan memiliki hasil yang konsisten (Zikmund, 2003). Uji reliabilitas dalam penelitian ini dengan melihat nilai $C A$ yang menunjukkan seberapa baik butirbutir pertanyaan berkorelasi secara positif satu sama lain Nilai $C A$ yang dapat diterima adalah 0,6 atau lebih (Zikmund, 2003). Penelitian lain menekankan bahwa nilai Alpha $(\alpha)$ minimum 0,7 lebih diinginkan. Selanjutnya melihat nilai CR. Menurut (Hair, Black, Babin, \& Anderson, 2010) tingkat realibilitas yang dapat diterima adalah $\geq 0,70$. Selanjutnya melihat nilai $A V E$, yang menunjukkan jumlah varians dari indikator-indikator yang diekstraksi oleh konstruk laten yang dikembangkan. Nilai $A V E$ yang tinggi menunjukkan bahwa indikator-indikator tersebut telah mewakili secara baik konstruk laten yang dikembangkan (Hair Jr, Black, Babin, \& Anderson, 2010) dalam (Ferdinand, 2014). Nilai AVE minimum untuk menyatakan bahwa keandalan telah tercapai adalah sebesar 0,50 (Wijanto, 2008) dan (Latan, 2013). Berdasarkan hasil pengolahan data diperoleh ke tiga variable penelitian memiliki nilai CA (Crombach's Alpha) $\geq 0,6$, CR (Composite Reliabilitas) $\geq 0,70$, dan AVE (Average Variance Extracted) $\geq 0,5$. Sehingga dapat dikatakan bahwa semua kontruk dalam penelitian ini memenuhi uji reliabilitas sehingga dapat di katakan reliable.

\subsubsection{Hasil Uji KMO and Bertlett's test}

Uji ini dilakukan untuk mengetahui seberapa layak data yang dimiliki untuk dianalisis lebih lanjut. Uji Kaiser Meyer Olkin (KMO) and Bartlett's Test merupakan statistik yang dapat menjelaskan tentang proporsi keragaman pada setiap variabel common variance (butir pertanyaan dalam kuesioner) atau keragaman yang disebabkan oleh faktor tertentu (underlying factor). 
Tabel 2. Hasil Uji KMO and Bartlett's Test

\begin{tabular}{|ll|r|}
\hline Kaiser-Meyer-Olkin Measure of Sampling & .721 \\
Adequacy. & Approx. Chi-Square & 187.504 \\
Bartlett's Test of & $\mathrm{df}$ & 3 \\
Sphericity & Sig. & .000 \\
\hline
\end{tabular}

Sumber : Data primer diolah

Dari hasil pengujian KMO and Bartlett's Test diperoleh nilai KMO 0,721 $\geq 0,5$ dengan tingkat signifikan 0,000 . Ini berarti semua item variabel serta indikator dalam penelitian ini dapat dikatakan layak untuk dijadikan sebagai data penelitian.

\subsubsection{Analisis Structural Equation Modelling (SEM)}

Dari Gambar 2 di bawah ini diperoleh hasil analisis data bahwa berdasarkan pengujian kelayakan model secara keseluruhan dapat dikatakan Good fit dan memenuhi kriteria GoodnessOff-Fit atau memenuhi syarat Cut-Off-Value yang telah ditentukan. Sehingga dapat disimpulkan bahwa konstruk-konstruk yang digunakan dalam penelitian ini sudah mencerminkan variabel laten endogen (sifat materialisme) serta variabel laten eksogen (impulsive buying dan compulsive buying) yang di analisis berserta masing-masing indikator.

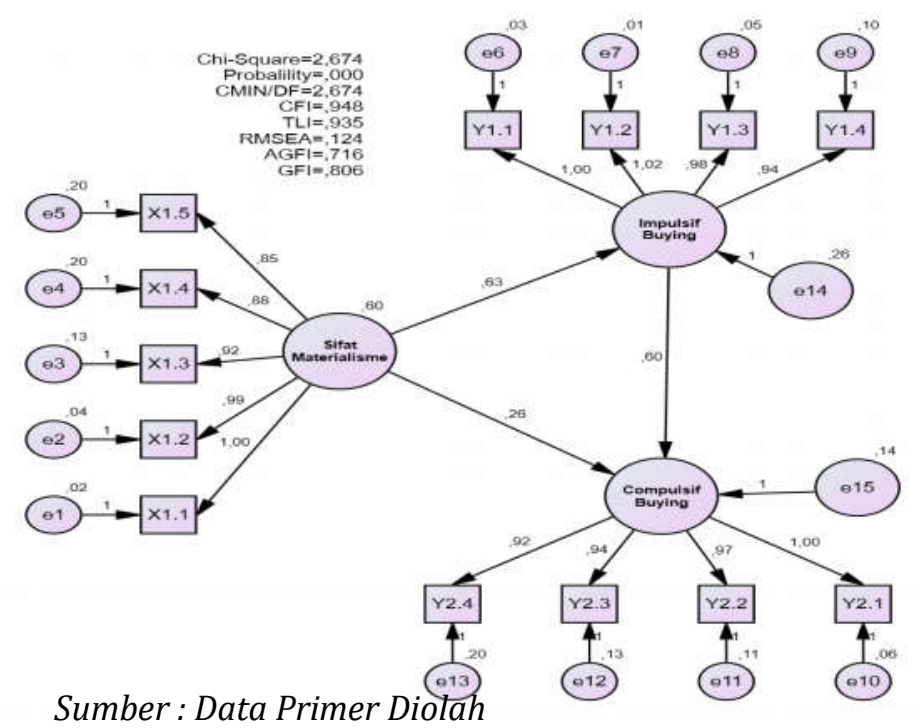

Gambar 2. Diagram Jalur Pengujian Hipotesis

\subsubsection{Hasil Uji Hipotesis}

Hasil pengujian hipotesis dilakukan dengan melihat nilai critical ratio (CR) dan nilai signifikan $p$ sebagai hasil dari pengolahan data yang dibandingkan dengan batasan statistik yang disyaratkan. Nilai critical ratio yang dipersyaratkan adalah diatas 1,96 dan nilai probabilitas yang disyaratkan adalah di bawah 0,05 . Jika hasil dari pengolahan data memenuhi persyaratan tersebut, maka hipotesis dalam penelitian yang diajukan dinyatakan dapat diterima. Masingmasing pengujian hipotesis dalam penelitian ini akan dibahas pada Tabel 3: Berdasarkan hasil output analisis jalur SEM yang dilakukan, dapat diketahui tingkat signifikansi pengaruh dan nilai critical ratio (cr) yang merupakan nilai t-value. Hasil ini digunakan untuk pengujian hipotesis penelitian yang diajukkan sebagai berikut. 


\begin{tabular}{|c|l|c|c|c|c|c|}
\hline \multicolumn{9}{c}{ Tabel 3. Hasil Full Model Structural Equation Modeling (SEM) } \\
\hline Hipotesis & \multicolumn{1}{c|}{ Path } & $\boldsymbol{\beta}$ & $\boldsymbol{t}$-value & $\boldsymbol{P}$ & Label & Kesimpulan \\
\hline H1 & $\begin{array}{l}\text { Sifat Materialisme } \rightarrow \\
\text { Impulsive Buying }\end{array}$ & 0,63 & 9,337 & $* * *$ & Sig. & Mendukung H1 \\
\hline H2 & $\begin{array}{l}\text { Sifat Materialisme } \rightarrow \\
\text { Impulsive Buying }\end{array}$ & 0,26 & 3,576 & $* * *$ & Sig. & Mendukung H2 \\
\hline H3 & $\begin{array}{l}\text { Impulsive Buying } \rightarrow \\
\text { Compulsive Buying }\end{array}$ & 0,60 & 7,290 & $* * *$ & Sig. & Mendukung H3 \\
\hline
\end{tabular}

Keterangan( ${ }^{* * *}$ ) tingkat Sig<0,001

Sumber : Data primer diolah

\subsection{Pembahasan}

\subsubsection{Hipotesis 1: Sifat Materialisme $\rightarrow$ Impulsive Buying}

Berdasarkan hasil pengolahan data dengan permodelan SEM diketahui bahwa nilai critical ratio (CR) untuk pengaruh antara variabel sifat materialisme terhadap impulsive buying seperti terlihat pada Tabel 3 adalah sebesar 9,337 dengan $P<0,001\left({ }^{* * *}\right)$. Kedua nilai ini menunjukkan hasil yang memenuhi syarat, yaitu diatas 1,96 dengan $P$-value $<0.05$. Sementara nilai kofisien jalur $(\beta)$ Sebesar 0,63. Ini menunjukkan sifat materialisme memiliki kontribusi serta pengaruh yang positif signifikan terjadinya impulsive buying secara online. Ini bermakna bahwa semakin tinggi sifat materialisme dalam berbelanja secara online maka akan semakin tinggi pula impulsive buying terjadi. Sehingga hipotesis 1 pada penelitian ini diterima.

Hasil penelitian ini di dukung oleh hasil penelitian yang dilakukan oleh Prawira Laksana \& Suparna (2015) yang menunjukkan bahwa sifat materialisme berpengaruh positif dan signifikan terhadap impusive buying. Hasil penelitian ini juga konsisten dengan penelitian Turkyilmaz, et al. (2015) yang menyatakan bahwa faktor psikologis konsumen seperti sifat materialisme dapat memicu seseorang melakukkan impulsive buying secara online. Temuan terbaru dari penelitian yang dilakukan oleh Ahn \& Kwon (2020) mengungkap bahwa berdasarkan teori aktivasi sifat, memiliki dampak pada pengaruh positif dan negatif perilaku impulsive buying. Faktor emosi/perasaan pelanggan memediasi hubungan antara kecenderungan impulsive buying dan perilaku. Temuan ini meningkatkan pemahaman tentang psikologis impulsive buying konsumen.

Remaja yang memiliki sifat materialisme yang tinggi dalam dirinya tentunya menganggap kepemilikan suatu barang seperti salah satunya produk fashion adalah suatu hal yang penting dalam hidupnya. Tidak bisa dipungkiri, kepemilikan sesuatu materi menentukan eksistensi seseorang dalam lingkungan atau komunitasnya. Sehingga ketika konsumen menganggap suatu barang tertentu penting dalam hidupnya sebagai ukuran kesuksesan dan kebahagiaan, konsumen yang materialisme tidak akan menunda untuk melakukkan impulsive buying. Hal ini terlihat dari indikator "kepemilikan barang penting dalam hidup" dan "membeli banyak barang membuat bahagia" memicu konsumen melakukan pembelian secara "spontan" maupun membeli "tanpa berpikir panjang". Artinya, ketika remaja menganggap penting kepemilikan suatu barang maka konsumen tersebut tidak akan berpikir panjang untuk segera melakukan pembelian. Selain itu, ketika "kepemilikan barang penting dalam hidup", konsumen akan "cenderung membeli banyak barang meskipun tidak begitu dibutuhkan" serta "tidak mempertimbangkan konsekuensi". Demikian halnya dengan indikator "membeli banyak barang membuat bahagia". Artinya, ketika barang yang dimiliki begitu penting dalam hidup dan memberikan kebahagiaan, maka konsumen tersebut tidak akan banyak pertimbangan dalam berbelanja sehingga impulsive buying secara online terjadi.

\subsubsection{Hipotesis 2: Sifat Materialisme $\rightarrow$ Kecenderungan Compulsif Buying}

Berdasarkan hasil pengolahan data dengan permodelan SEM diketahui bahwa nilai critical ratio (CR) untuk pengaruh antara variabel sifat materialisme terhadap kecenderungan compulsive buying yang terdapat pada Tabel 3 adalah sebesar 3,576 dengan $P<0,001\left({ }^{* * *}\right)$. Kedua nilai ini menunjukkan hasil yang memenuhi syarat, yaitu diatas 1,96 dengan $P$-value 
$<0.05$. Sementara nilai koefisien jalur $(\beta)$ Sebesar 0,26 . Ini menunjukkan sifat materialisme memiliki kontribusi serta pengaruh yang positif signifikan terjadinya kecenderungan compulsive buying secara online. Ini bermakna bahwa semakin tinggi sifat materialisme dalam berbelanja secara online maka akan semakin tinggi pula kecenderungan compulsive buying terjadi. Sehingga hipotesis 2 pada penelitian ini diterima. Hasil penelitian ini di dukung oleh penelitian yang dilakukan oleh Eren, et al. (2012) dan penelitian Alqurianisha, et al. (2020) yang menyatakan bahwa ada hubungan antara materialisme dengan compulsive buying. Kajian empiris yang dilakukan oleh Shahid, et al. (2012) menemukan sifat materialsme memiliki relasi yang sangat erat dan signifikan terhadap kecenderungan compulsive buying pada perilaku konsumen. Hal ini mengkonfirmasi bahwa kepemilikan suatu benda dapat menunjukkan kesuksesan dan memberikan kebahagiaan pada seseorang dan memandang kepemilikan sebagai pusat kehidupan. Perilaku tersebut berpotensi tinggi mengarah pada terjadinya cenderung compulsive buying.

Kajian yang dilakukan Anggriani (2017) mengungkapkan sebuah kenyataan bahwa remaja sudah mengadopsi secara kuat nilai materialisme berupa kepemilikan suatu barang. Nilai ini muncul karena adanya pengaruh sosial media, televisi, lingkungan pertemanan, dan bahkan dari lingkungan keluarga yang mulai menanamkan bahwa dengan memiliki sesuatu menjadikan seseorang menjadi berarti dan dihargai. Nilai materialisme juga tumbuh karena pengaruh keinginan agar diterima dalam kelompok tertentu dengan baik. Tidak bisa dipungkiri, sebagian individu merasa bahwa kepemilikan sesuatu membawa arti penting dalam kehidupannya. Ketika konsumen menganggap kepemilikan adalah suatu yang berarti atau penting, maka konsumen tersebut tentunya akan terus melakukan pembelian sehingga menjadikan belanja sebagai suatu rutinitas serta gaya hidup yang menyenangkan sehingga secara tidak langsung konsumen tersebut akan menghabiskan uangnya untuk memenuhi hastrat belanja dan hal ini dapat mengarah pada kecenderungan compulsive buying. Menurut Gwin, et al,. (2005) dalam Anggriani (2017) menyatakan bahwa dampak jangka panjang compulsive buying yaitu dapat memicu terjadinya kebangkrutan, hutang yang menumpuk dan lain-lain. Sementara dampak jangka pendek yaitu konsumen dapat langsung merasakan kepuasan dan kesenangan ketika proses belanja berlangsung.

\subsubsection{Hipotesis 3: Impulsive Buying $\rightarrow$ Compulsive Buying}

Dari hasil uji hipotesis pada Tabel 3 bermakna semakin tinggi impulsive buying terjadi maka dapat menggarah pada kecenderungan compulsive buying. Hasil olah data diperoleh nilai CR sebesar 7,290, jauh diatas 1,96, nilai koefisien jalur $\beta ; 0,60$ dengan nilai signifikan probability $P<0,001{ }^{(* *)}$ kurang dari 0,05 . Sehingga dapat ditarik kesimpulan bahwa hipotesis ke 5 dalam penelitian ini diterima. Hasil penelitian ini didukung oleh penelitian yang dilakukan oleh Anggriani (2017), di mana hasil penelitian menunjukan terdapat pengaruh yang positif dan signifikan antara impulsive buying terhadap kecenderungan compulsive buying. Semakin sering sering seseorang melakukan impulsive buying dalam jangka panjang akan menjadikannya sebagai pembeli dengan perilaku membeli yang berlebihan dan secara terus menerus dapat mengarah pada kecenderungan compulsive buying.

Konsumen Indonesia dikenal sebagai masyakat yang konsumtif dan royal dalam berbelanja sehingga hal ini berpengaruh pada pola belanja dan konsumsi konsumen dalam hal ini adalah impulsive buying maupun kecenderungan compulsive buying. Ketika konsumen berbelanja secara impulsive, konsumen tersebut tidak akan mempertimbangkan manfaat dari produk yang dibeli karena pembelian yang dilakukkan secara leflek, tiba-tiba, spontan dan tanpa ada niatan belanja sebelumnya yang biasanya mencari kesenangan serta kepuasan sesaat. Hal ini bisa jadi disebabkan karena berbagai hal seperti adanya discount atau adanya faktor pemenuhan kebutuhan. Sementara konsumen yang melakukan compulsive buying ketika berbelanja lebih kepada kegiatan belanjanya seperti untuk memperbaiki suasana hati menjadi lebih baik, ingin menghabiskan uang sehingga konsumen yang compulsive cenderung membeli sesuatu tetapi tidak perduli apa yang dibeli. Ini dikarenakan konsumen yang compulsive lebih kepada aktivitas belanjanya dari pada keinginan untuk memiliki produknya. Sebaliknya konsumen yang compulsive akan merasa gelisah jika tidak berbelanja. 


\section{Kesimpulan dan Rekomendasi}

\subsection{Kesimpulan}

Hasil analisis dengan permodelan Struktural Equation Modeling (SEM) menunjukan bahwa terdapat pengaruh dan hubungan yang positif dan signifikan antara sifat materialisme terhadap impulsive buying. Demikian halnya dengan variabel sifat materialisme terhadap kecenderungan compulsive buying yang berpengaruh positif dan signifikan, serta pengaruh yang positif dan signifikan antara impulsive buying terhadap kecenderungan compulsive buying.

Hasil penelitian ini juga membuktikan bahwa faktor psikologis konsumen seperti sifat materialisme dapat menjadi penyebab terjadinya impulsive buying maupun kecenderungan compulsive buying di kalangan remaja yang dilakukan secara online. Temuan inipun membuktikan bahwa impulsive buying biasanya dilakukan secara offline akan tetapi dapat juga terjadi ketika konsumen berbelanja secara online. Penelitian ini juga mengkonfirmasi bahwa Kecenderungan compulsive buying yang selama ini sering terjadi di Negara-negera maju dengan sampel konsumen dengan gaya hidup mewah perkotaan dapat juga terjadi di Negara berkembang dengan sampel penelitian remaja lokal di Kota Mataram .

Dalam penelitian ini terdapat keterbatasan yaitu: Penelitian ini hanya sebatas pada variabel Sifat Materialisme terhadap Impulsive Buying dan Kecenderungan Compulsive Buying. Kedepan diharapkan agar dapat memperluas cakupan penelitian terkait Impulsive Buying maupun Kecenderungan Compulsive Buying secara Online dengan menambahkan variabelvariabel lain. Hal lain adalah jumlah responden yang dijadikan sampel penelitian masih relatif lebih kecil dibandingkan dengan jumlah remaja secara keseluruhan di Kota Mataram. Terakhir adalah tidak dibatasi pada kategori produk tertentu seperti fashion saja, tetapi menggunakan kategori produk yang lebih bervariasi sehingga hasil yang diperoleh dapat dibandingkan khususnya berkaitan dengan Impulsive Buying dan Kecenderungan Compulsive Buying secara Online.

\subsection{Rekomendasi}

Bagi pemasar online hendaknya terus meningkatkan perilaku impulsive buying maupun kecenderungan compulsive buying konsumen melalui strategi promosi penjualan yang efektif yang dapat memicu serta mempengaruhi psikologis konsumen untuk terus melakukan pembelian impulsive maupun compulsive, karena ketika konsumen berbelanja secara impulsive maupun compulsive konsumen tersebut kurang menghiraukan manfaat atau utilitas utama dari suatu produk yang dibeli sebaliknya lebih mementingkan aspek kesenangan, hiburan, kepuasan serta ingin menyalurkan kebiasaan belanjanya dan hal ini sangat menguntungkan bagi pemasar.

Bagi penelitian selanjutnya, untuk mengkaji kembali penelitian variabel-variabel lain diluar dari variabel yang ada dalam penelitian ini. Hal ini dikarenakan perkembangan jumlah penguna internet yang ditunjang oleh kemajuan teknologi yang terus meningkat mengakibatkan perubahan baik pada perilaku pembelian konsumen serta dari segi psikologis konsumen. selain itu akan lebih menarik bagi penelitian selanjutnya untuk mencoba membandingkan variabel psikologis maupun perilaku belanja konsumen dilakukan secara online maupun secara offline.

\section{Daftar Pustaka}

Adamczyk, G., Capetillo-Ponce, J., \& Szczygielski, D. (2020). Compulsive Buying in Poland. An Empirical Study of People Married or in a Stable Relationship. Journal of Consumer Policy, 43(3), 593-610. https://doi.org/10.1007/s10603-020-09450-4

Ahn, J., \& Kwon, J. (2020). The role of trait and emotion in cruise customers' impulsive buying behavior: an empirical study. Journal of Strategic Marketing, 00(00), 1-14. https://doi.org/10.1080/0965254X.2020.1810743

Alqurianisha, J., Murdiyani, H., \& Poerwanto, A. (2020). Hubungan Antara Peranan Keluarga dan Materialisme Dengan Perilaku Compulsive Buying Online Pada Remaja Di Wilayah Kecamatan Bulak Surabaya. Psikosains, 15(1), 32-42. 
Anggriani, R. (2017). Influence of Materialism, Hedonic Motivation On Impulsive Buying, and Tendency to Compulsive Buying Online Among Mataram University Students. JMM UNRAM - Master of Management Journal, 6(2), 1-20. https://doi.org/10.29303/jmm.v6i2.107

Anggriani, R., Anggrawan, A., \& Cahyadi, I. (2020). Structural Analysis of the Equation Model on Store Atmosphere towards Hedonic Value and Consumer Impulsive Buying (Study at Majapahit Food Center). Jurnal Varian, 4(1), 61-70. https://doi.org/10.30812/varian.v4i1.851

Balik, D., Abraham, F., \& Tupamahu, S. (2020). Efek Moderasi Kontrol Diri pada Hubungan Sifat Materialisme Terhadap Pembelian Impulsif Online. 1(2).

Bighiu, G., Manolică, A., \& Roman, C. T. (2015). Compulsive Buying Behavior on the Internet. Procedia Economics and Finance, 20(15), 72-79. https://doi.org/10.1016/s22125671(15)00049-0

Eren, S. S., Eroğlu, F., \& Hacioglu, G. (2012). Compulsive Buying Tendencies through Materialistic and Hedonic Values among College Students in Turkey. Procedia - Social and Behavioral Sciences, 58, 1370-1377. https://doi.org/10.1016/j.sbspro.2012.09.1121

Ferdinand, A. T. (2014). Management Research Method (5th ed.). Semarang: Bp Undip.

Floh, A., \& Madlberger, M. (2013). Electronic Commerce Research And Applications The Role of Atmospheric Cues in Online Impulse-Buying Behavior. Electronic Commerce Research and Applications, 12(6), 425-439. https://doi.org/10.1016/j.elerap.2013.06.001

Hair, J. F., Black, W. C., Babin, B. J., \& Anderson, R. E. (2010). Multivariate Data Analysis. Hair (7th, 2010).pdf. Pearson.

Hair Jr, J. F., Black, W. C., Babin, B. J., \& Anderson, R. E. (2010). Multivariate Data Analysis Seventh Edition. New Jersey: Pearson Prentice Hall.

Latan, H. (2013). Structural Equation Model, Theory and Implementation of AMOS 21. Bandung: Penerbit AlfaBeta.

Made, D., \& Purnama, F. (2019). Hedonic Shopping Motivation, Shopping Lifestyle, Price Reduction toward Impulse Buying Behavior in Shopping Center. 3, 48-54.

Minor, M. J. . \&. (2012). Consumer Behavior (Erlangga, Ed.). Jakarta.

Prawira Laksana, K., \& Suparna, G. (2015). The Role Of Hedonist Motivation Mediates The Influence Of Materialism On Impulsive Purchasing Behavior Online. EE-Journal of Management University of Udayana, 4(6), 254896.

Richins, M. L., \& Dawson, S. (1992). A Consumer Values Orientation for Materialism and Its Measurement: Scale Development and Validation. Journal of Consumer Research, 19(3), 303. https://doi.org/10.1086/209304

Shahid, R., Asif, K., Jamshed, khan K., Ahsan, A., \& Mah a Mobeen, A. (2012). The impact of materialism on compulsive consumption in Pakistan. African Journal of Business Management, 6(49), 11810-11818. https://doi.org/10.5897/ajbm11.1870

Taherdoost, H. (2016). Validity and Reliability of the Research Instrument: How to Test the Validation of a Questionnaire/ Survey in a Research. International Journal of Academic Research in Management, 5(3), 28-36. https://doi.org/10.2139/ssrn.3205040

Turkyilmaz, C. A., Erdem, S., \& Uslu, A. (2015). The Effects of Personality Traits and Website Quality on Online Impulse Buying. Procedia - Social and Behavioral Sciences, 175, 98-105. https://doi.org/10.1016/j.sbspro.2015.01.1179

Wijanto, S. H. (2008). Structure Equation Modeling dengan Lisrel.8.8.”. Yogyakarta: Graha Ilmu.

Zikmund, W. . (2003). Bussiness Research Metdhods" (Edition, 7). Thomson South Western: United States of America. 